\title{
Contribution to the Evaluation of Safety Barriers at the Treatment Section 'STRIPPER'
}

\author{
Ahcène AKNI \\ LITE Laboratory, Université Frères Mentouri, Constantine 1, Algeria, akni.ahcene@gmail.com \\ Rachid CHAIB \\ LITE Laboratory, Université Frères Mentouri, Constantine 1, Algeria, $\underline{\text { r3chaib@yahoo.fr }}$ \\ Ion VERZEA \\ “Gheorghe Asachi” Technical University, Iasi 700050, Romania, verzea2000@yahoo.com
}

\begin{abstract}
Algeria occupies an important place in all oil-producing countries. However, in recent years, industrial establishments have experienced a rapid increase in the number of major industrial accidents, where fires and explosions cause serious impacts on people, systems and the environment. In order to avoid these dangerous phenomena, industrialists are obliged to put in place risk control measures whose role is to prevent the occurrence of such phenomena or to limit their consequences. Thus, and because of the unsatisfactory safety results achieved during the past period, The Algerian hydrocarbons company (Sonatrach) has tried to reinforce the security barriers at these industrial sites. From there the objective of this paper appears that is the evaluation of these safety barriers by checking their performances through the development of quantitative or semi-quantitative approaches. This work is devoted to the application of a combination of three methods: HAZOP, ADE and LOPA at the level known as the "Stripper" of the TFT industrial zone. The collection of information on the Stripper system is ensured by the two methods HAZOP and ADE. However, the LOPA method is used to evaluate protective layers whose objective is to control and improve the system's security barriers against future aggressions and undesirable incidents.
\end{abstract}

\section{Keywords}

HAZOP, LOPA (Layer of Protection Analysis), safety barriers, protection, SIL (Safety Integrity Level), performance criteria, SIS (Safety Instrumented System)

\section{Introduction}

The principle of a hazard study based on a risk analysis which should characterize not only the potential severity but also the probability of occurrence of accidents. Therefore, risk analysis and risk assessment can be conducted, depending on the quality of the information and the data collected on the system in several ways, qualitative, semi-quantitative or quantitative $[1,2]$. Consequently, it is essential to know the safety system which contributes to ensuring the safe operation of the installations. As the hydrocarbons industry is subject to a wide variety of incidents or serious situations that can seriously disrupt its operation, even damage it and even destroy it. Safety barriers are important means of prevention that must be installed to control deviations from the operating parameters of industrial processes [3]. Therefore, safety barriers are used to avoid, control, and reduce any deviation of energy possible. From now on, it is on the basis of the performance of each of the safety barriers (implemented to fulfill a safety function) that the control of the risks of an installation can be demonstrated, in particular by reducing the risk induced by the barriers of security $[4,5]$.

\section{Working Methodology}

\subsection{Principle of the LOPA method}

LOPA is a semi-quantitative method oriented barriers [6] which requires in its approach an evaluation of the independent protective layers put in place in an industrial system in order to be able to control the risks of accidents inherent to this system. As with any security barrier, a protective layer 
(IPL) can be an element, system, device, action or procedure to perform a certain safety function to prevent an accident scenario and / effects [7]. The latter makes it possible to evaluate the probability of failure on demand (PFD) of each protective layer. Once the initiator events are identified and their frequencies of occurrence are adjusted, LOPA allows the determination of the frequency of occurrence of each accident scenario. The frequency of an accident scenario is given by the following equation [6]:

$$
f_{i}^{C}=f_{i}^{I} \cdot \prod_{j=1}^{j} P F D_{i j}
$$

where:

$f_{i} C^{C}$ - frequency of consequence $(C)$ for the initiating event (i);

$f_{i} I$ - frequency of initiating event;

$P F D_{i j}$ - probability of failure at the request of IPL which responds to the occurrence of the consequence.

Once the accident scenario is estimated in terms of the frequency of the consequence, it remains to decide whether this accident scenario is acceptable or not. This decision will be taken through an assessment of this risk in relation to the criteria Acceptable at the beginning of the analysis. Figure 1 shows generally the different types of IPLs found in the majority of chemical and petrochemical systems and industrial plants [6,7].

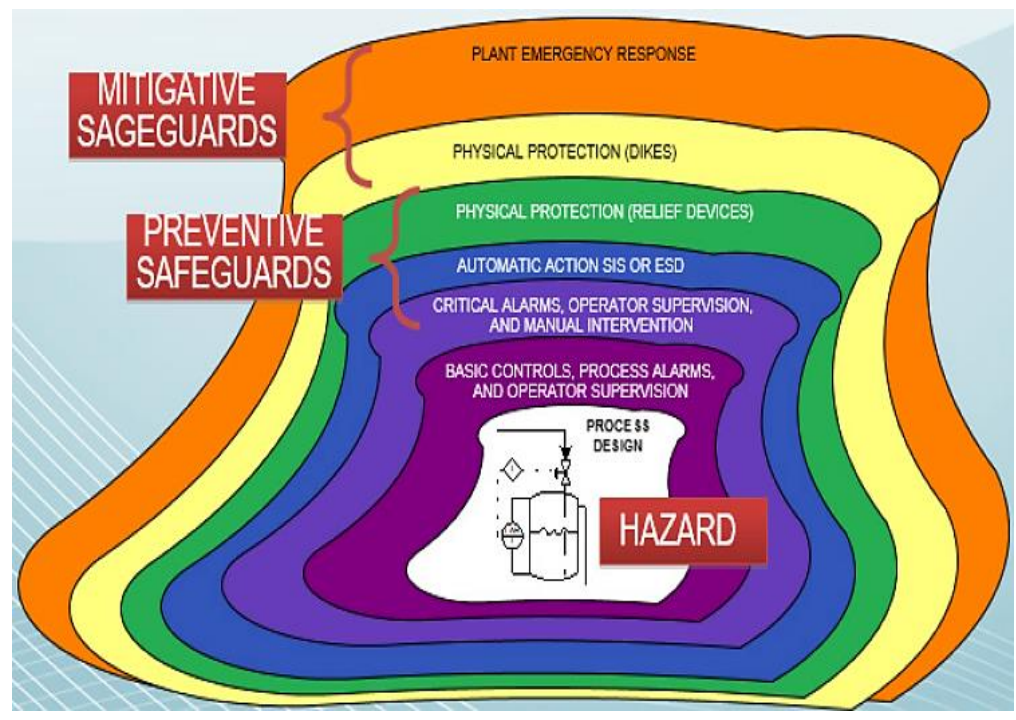

Fig. 1. Risk reduction layers [8]

\subsection{Procedure of the LOPA method}

The approach is based on the evaluation of accident scenarios in relation to the risk acceptability criteria, see Figure 2.

\subsection{Technical safety barriers}

A security device is in general a unitary, autonomous element, the purpose of which is to fulfill a safety function. Figure 3 shows a typology of safety barriers. A safety barrier is called the Protection Layer Independence (IPL). This independence property will allow an IPL to perform its security function independently of any common cause or failure. Thus, the evaluation of the performance of the barriers consists of the evaluation of their efficiency of their response time and their trust level. Consideration is also given to maintainability and testability criteria, which guarantee the level of performance over time [10]. Its performance should not be degraded by the occurrence of the initiating event [11].

Figure 4 explains the process of selecting IPL. 


\section{Presentation of the "Processing Section"}

The CS2 station (TFT-SONATRACH) is designed to recover gas initially flared at the separation centers, treat them by dehydration and compress them to $80 \mathrm{~kg} / \mathrm{cm}^{2}$. The high-pressure and lowpressure gas enters the flasks D101 and D201 respectively at the pressures of $6.2 \mathrm{~kg} / \mathrm{cm}^{2}$ and $0.8 \mathrm{~kg} / \mathrm{cm}^{2}$, where it is cleared of its liquid.

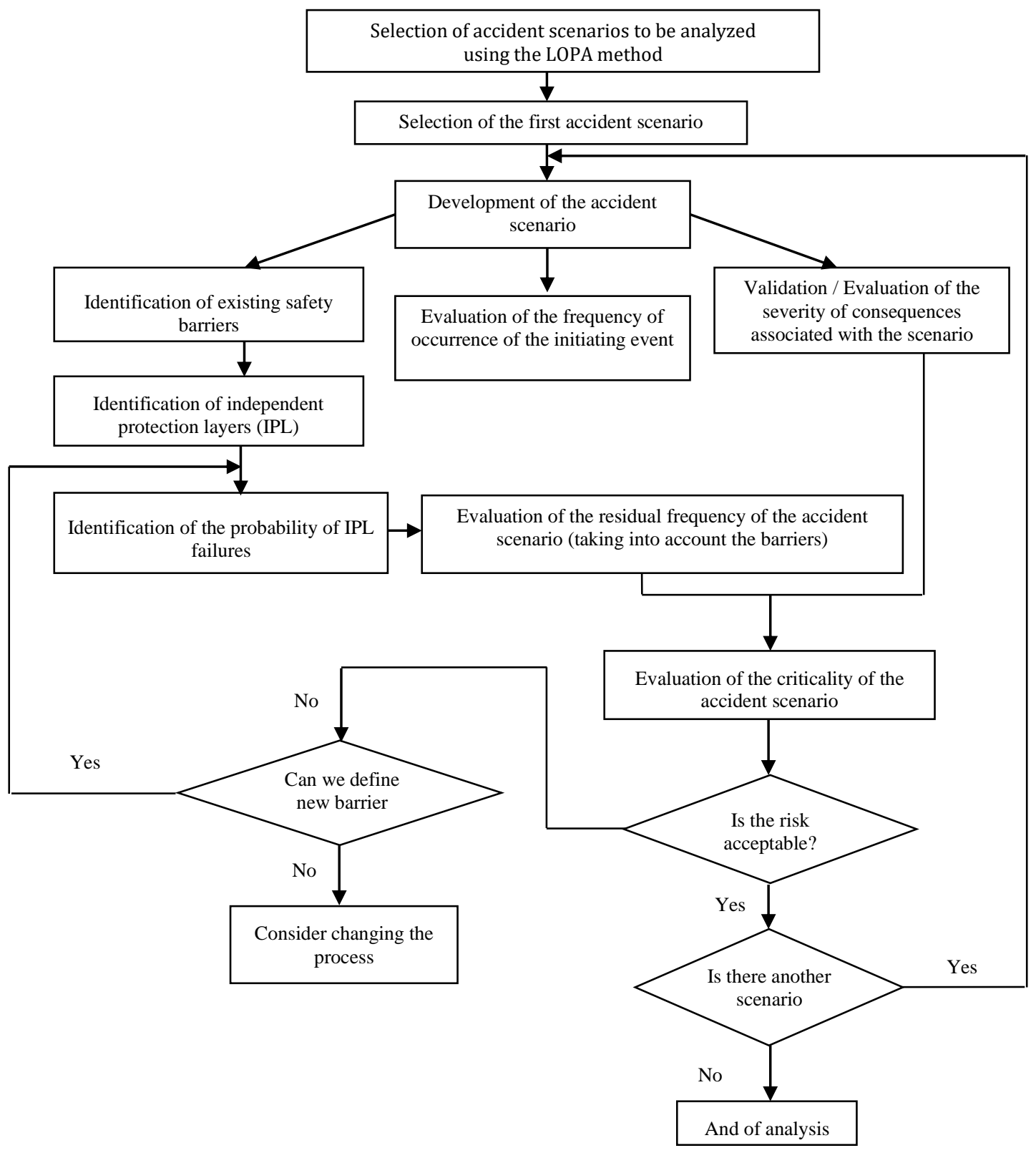

Fig. 2. General process of the LOPA method [9]

The dry gas from the D-301A/B/C is divided into two flows, one of which is heat exchanged with gas from the low pressure separator (D-402) in the gas / (E-402) and the other with liquid from the high pressure separator (D-401) in the gas / liquid exchanger (E-403A/B) [13].

These two gas flows are then combined again and enter the H.P. separator (D-401), from which the liquid extract is sent to stripper (C-401). In C-401, a slight gaseous fraction is extracted from the condensate. While the bottom liquid is circulated under the action of the Stripper reboiler pump (G-40lA/B) and reboiled using the stripper reboiler (H-40l). The bottom condensate is sent to the center CS2 after being cooled by the condensate cooler (E-401). 


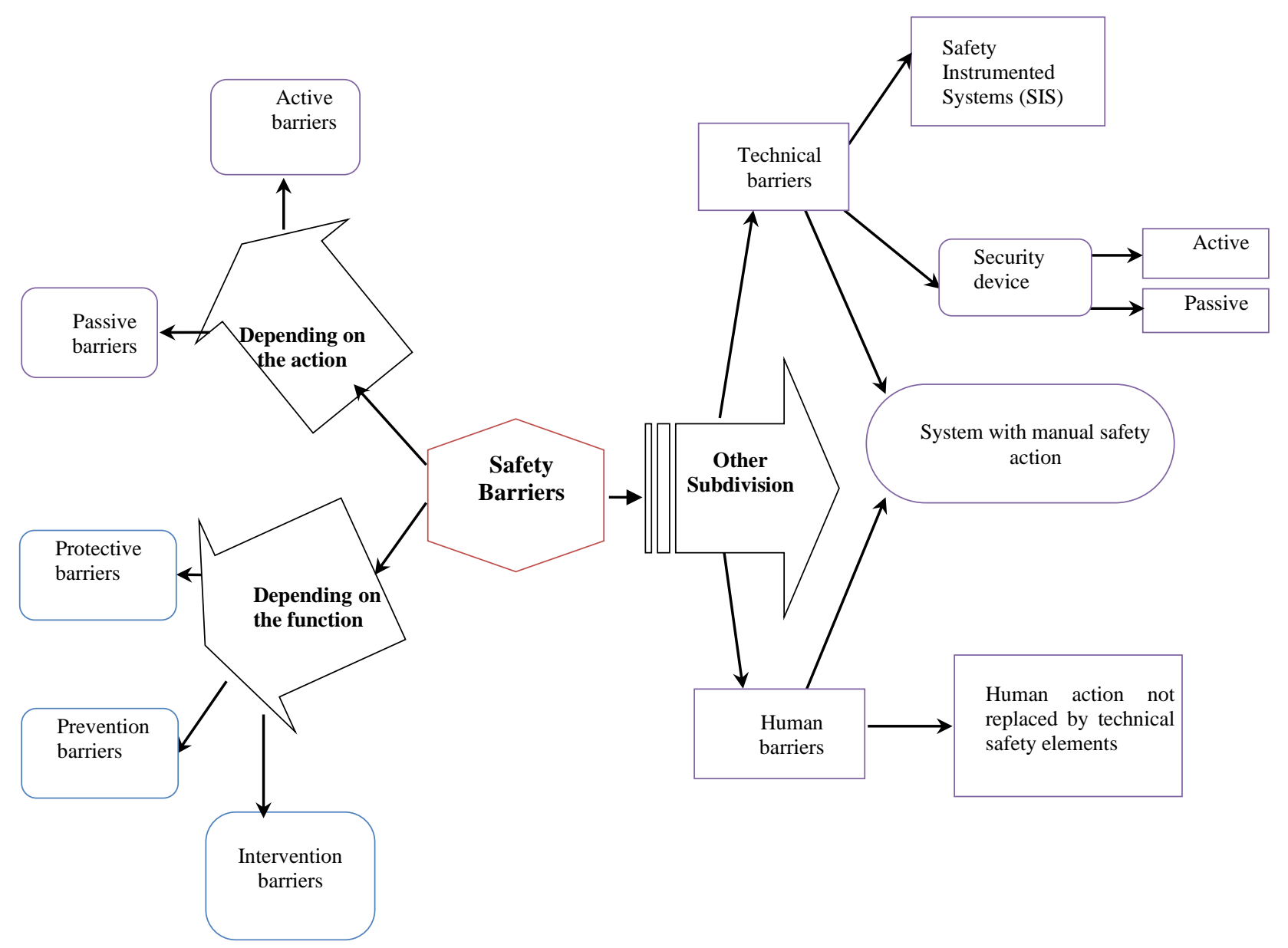

Fig. 3. Typology of safety barriers [12]

Is independence verified?
Can the probability of failure be assessed and justified?
Can effectiveness be demonstrated and justified?

Is the response time in line with the scenario kinetics?

The barrier can be retained as IPL

Fig. 4. Process for selecting a barrier as an IPL [12]

The gas from the separator H.P. is adiabatically expanded in the D-402 to reduce its dew point and condensed liquid is sent to C-401, Figure 5.

The processing section has a function to ensure production of the treated gas and condensate extraction and degassing [13]. It consists of:

- Two separators,

- A gas / gas exchanger and a gas / liquid exchanger,

- A stripper,

- A stripper reboiler,

- Two reboiler pumps,

- Condensate evacuation systems with a cooler. 


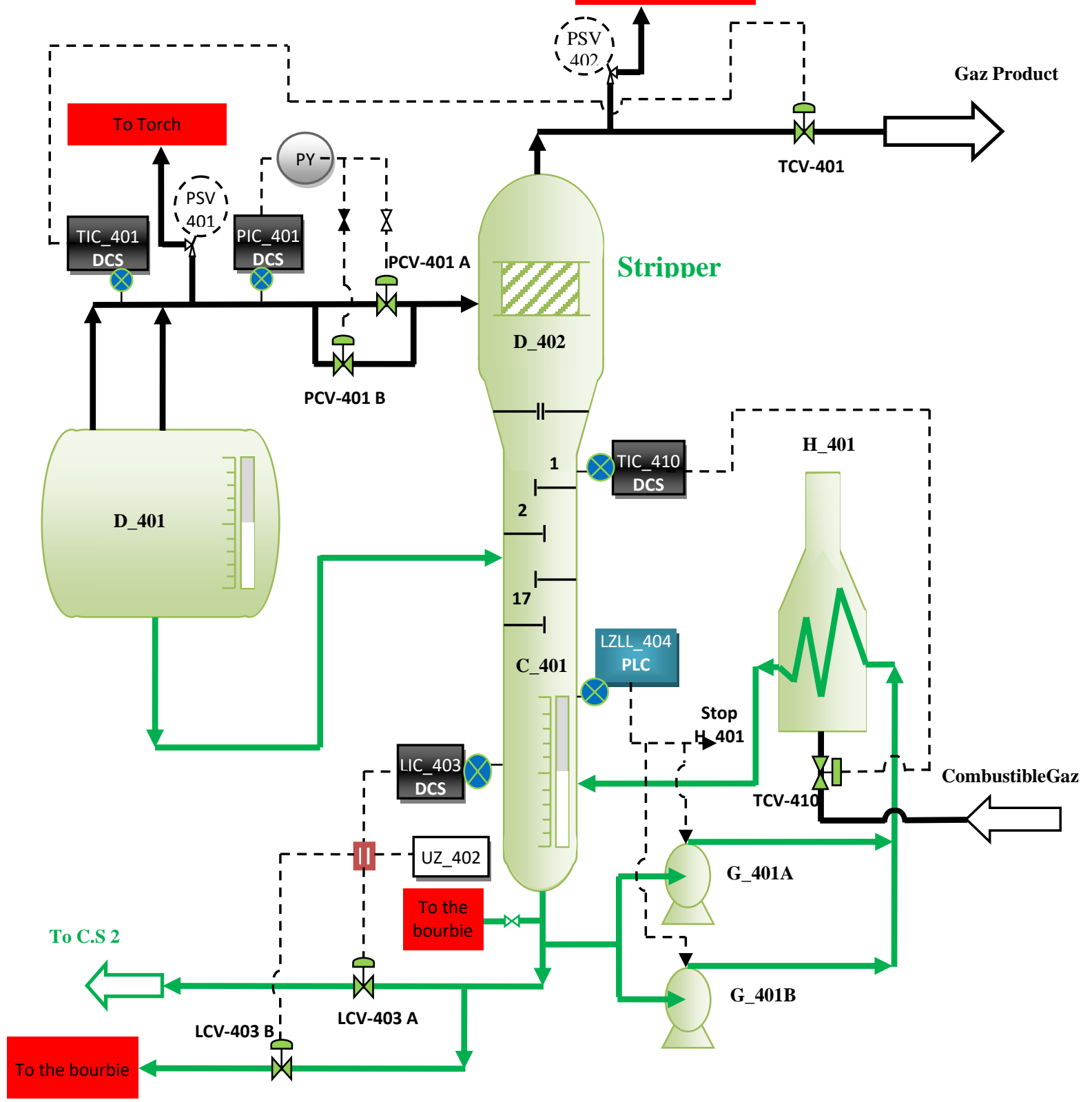

Fig. 5. System Overview "Treatment Section" [12]

\section{Functional Analysis of the Studied System}

\subsection{Main characteristics of the Stripper equipment}

Table 1 describes the characteristics of Stripper.

Table 1. Main characteristics of Stripper [12]

\begin{tabular}{ll}
\hline Equipment & Stripper (D-402, C-401) \\
\hline Service & $\begin{array}{l}\text { Separation of gas and condensate at column C_401 and } \\
\text { accumulated gas at balloon D_402 }\end{array}$ \\
\hline Operating Pressure & $23 \mathrm{Bar}$ \\
\hline \multirow{2}{*}{ Operating Temperature } & $\begin{array}{l}\mathrm{D}-402 /-3.7^{\circ} \mathrm{C} \\
\mathrm{C}-401 / 45^{\circ} \mathrm{C}\end{array}$ \\
\hline
\end{tabular}




\subsection{Description of the control and regulation system (the Stripper)}

\subsubsection{Under control and regulation system}

Control the Stripper concerns the condensate level and temperature in the C_401 column and the gas pressure in the D-402 balloon. In this case, it is necessary to define the operating modes of this system.

Table 2 shows the various control and regulation parameters of the under system.

Table 2. Structural and functional decomposition of control loops [12]

\begin{tabular}{|c|c|c|}
\hline $\begin{array}{l}\text { Under } \\
\text { system }\end{array}$ & Equipment & Component \\
\hline \multirow{4}{*}{$\begin{array}{l}\text { Ss1: under } \\
\text { control and } \\
\text { regulation } \\
\text { system } \\
\text { [control and } \\
\text { regulation of } \\
\text { process } \\
\text { parameters] }\end{array}$} & $\begin{array}{l}\text { E.1.1: level control } \\
\text { loop (LIC-403) } \\
\text { [control and } \\
\text { regulation of the } \\
\text { condensate level in } \\
\text { the Stripper column] }\end{array}$ & $\begin{array}{l}\text { C.1.1.1: Level sensor LIH [measures the high level in the column and } \\
\text { transmits it to the DCS]. } \\
\text { C.1.1.2: Level LIL sensor [measures the low level in the column and } \\
\text { transmits it to the DCS]. } \\
\text { C.1.1.3: DCS (solver) [adaptation of the liquid level in the column to } \\
\text { an action on valve LCV_403A with audio-visual alarm]. } \\
\text { C.1.1.4: valve LCV_403A [of the regulating type to regulate the flow } \\
\text { rate of condensate to CS2]. }\end{array}$ \\
\hline & $\begin{array}{l}\text { E.1.2: Temperature } \\
\text { control loop (TIC- } \\
\text { 410) [temperature } \\
\text { control and } \\
\text { regulation in the } \\
\text { Stripper column] }\end{array}$ & $\begin{array}{l}\text { C.1.2.1: TI temperature sensor [measures the condensate } \\
\text { temperature at the inlet of column C- } 401 \text { and transferred to the DCS]. } \\
\text { C.1.2.2: DCS (solver) [adaptation of the lowering or increase of the } \\
\text { condensate temperature in the column by action on the TCV410 } \\
\text { valve]. } \\
\text { C.1.2.3: the valve TCV410 [opening or closing percentage to adjust } \\
\text { the fuel gas reboiler]. }\end{array}$ \\
\hline & $\begin{array}{l}\text { E.1.3: Pressure } \\
\text { control loop (PIC- } \\
\text { 401) [control and } \\
\text { gas pressure } \\
\text { decrease that } \\
\text { entered the balloon } \\
\text { Stripper] }\end{array}$ & $\begin{array}{l}\text { C.1.3.1: PI pressure sensor [measures the gas pressure at the inlet } \\
\text { balloon D402]. } \\
\text { C.1.3.2: DCS (solver) [adaptation of the lowering or increase of the } \\
\text { gas pressure in the tank by action on the PCV401A and PCV401B } \\
\text { valves by the transmitter as required]. } \\
\text { C.1.3.3: the valve PCV401A [gas pressure lowering entered the } \\
\text { balloon D402]. } \\
\text { C.1.3.4: the valve PCV401B [lowered gas pressure entered in the } \\
\text { balloon D402]. }\end{array}$ \\
\hline & $\begin{array}{l}\text { E.1.4: Temperature } \\
\text { control loop (TIC- } \\
\text { 401) [temperature } \\
\text { control and } \\
\text { regulation in the } \\
\text { Stripper column] }\end{array}$ & $\begin{array}{l}\text { C.1.4.1: TI temperature sensor [measures the gas temperature at the } \\
\text { inlet of the D402 flask and transferred to the DCS]. } \\
\text { C.1.4.2: DCS (solver) [adaptation of the lowering or increase of the } \\
\text { gas temperature at the outlet of the tank by action on the TCV401 } \\
\text { valve]. } \\
\text { C.1.4.3: the TCV401 valve [opening or percentage fastener to adjust } \\
\text { the gas temperature at the outlet of balloon D402]. }\end{array}$ \\
\hline
\end{tabular}

4.2.2. Instrumented safety system (SIS)

Table 3 shows the structural and functional decomposition of the instrumented safety system.

Table 3. Structural and functional decomposition of control loops [12]

\begin{tabular}{llll}
\hline System & Under system & Equipment & Component \\
\hline & S.s1: very low level & $\begin{array}{l}\text { E.1.1: Detector } \\
\text { block }\end{array}$ & $\begin{array}{l}\text { C.1.1.1: LZLL 404 level sensor [measures the low } \\
\text { level in the column and transmits it to the PLC] }\end{array}$ \\
\cline { 3 - 4 } $\begin{array}{l}\text { S: Safety } \\
\text { Instru- } \\
\text { mented }\end{array}$ & $\begin{array}{l}\text { function LZLL- } \\
\text { 404[emergency stop } \\
\text { System }\end{array}$ & $\begin{array}{l}\text { E.1.2: Treatment G-401 A/B pumps } \\
\text { block }\end{array}$ & $\begin{array}{l}\text { C.1.1.2: PLC (solver) [Level monitoring in the } \\
\text { G-401 A / B pumps and H-401 Reboiler stop with } \\
\text { and H-401 Reboiler] }\end{array}$ \\
\cline { 3 - 4 } & $\begin{array}{l}\text { E.1.3: Actuator } \\
\text { block }\end{array}$ & $\begin{array}{l}\text { C.1.1.3: G-401 A / B pumps which feed the } \\
\text { following procedure. }\end{array}$ \\
\hline
\end{tabular}




\subsubsection{Description of the alarm system}

The alarm system is a technical safety barrier / safety devices. The alarms are quoted as follows:

- Low level condensate alarm in column C401: LALL-404 started at 18\%,

- High level condensate alarm in column C401: LAH-403 started at 75\%,

- Low level condensate alarm in column C401: LAL-403 started at 30\%,

- High temperature gas alarm: TAH-401 started at $30^{\circ} \mathrm{C}$.

\subsubsection{Description of the monitoring system}

a) Liquid control loop architecture LIC-403 (Figure 6): The range of action of this loop is $18 \%$ to $75 \%$ condensate in the column.

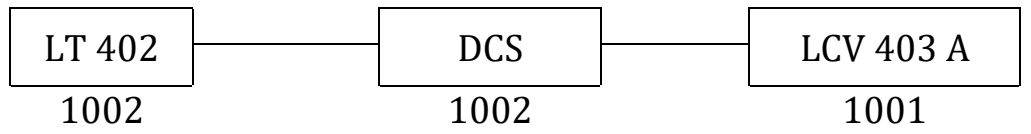

Fig. 6. Control loop architecture LIC-403

b) Temperature control loop architecture TIC-410 (Figure 7): The range of action of this loop is $103^{\circ} \mathrm{C}$.

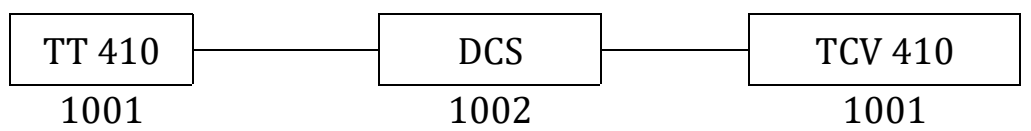

Fig. 7. Control loop Architecture TIC-410

c) Pressure loop architecture PIC-401 (Figure 8): The range of action of this loop is 79 Bar.

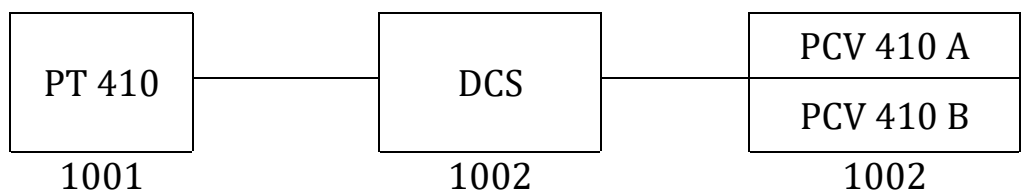

Fig. 8. Control loop architecture ICP 401

\subsubsection{Description of emergency stop system ESD}

Safety of very low level LZLL-404 (Figure 9). The system triggering threshold LZLL-404 is of the order of $18 \%$ of liquid.

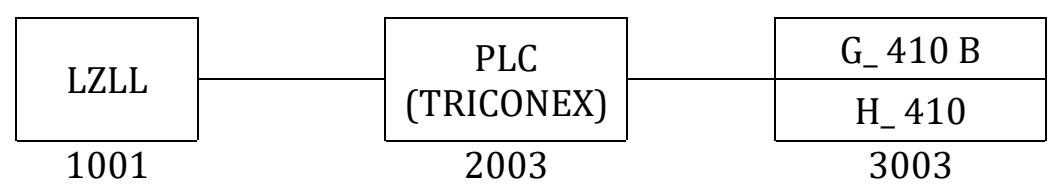

Fig. 9. LZLL-401 Safety Instrument System Architecture

\subsubsection{Description of Safety Valve}

There are four safety valves (PSV-401 and PSV-402 (A / B / C)) which protect:

- The entry into the D-402 balloon by the PSV-401 with a trigger threshold of 94 Bars.

- The D-402 balloon itself by the PSV-402 (A / B / C) with a trigger threshold of 27.5 Bars.

\section{Dysfunctional Analysis}

The analysis of system failures is to identify conditions that can lead to failures and know their impact on the dependability of the design level systems or already operational.

\subsection{Scenario analysis}

The LOPA method is based on the elements of its scenarios, based on the results provided by the HAZOP. The scenarios used are presented in Table 4. 
RECENT, Vol. 21, no. 3(62), 2020

Table 4. Initiating events and selected scenarios [12]

\begin{tabular}{|c|c|}
\hline The selected scenarios & Initiating events \\
\hline $\begin{array}{l}\text { 1st } \text { scenario: Formation of sheet of liquid and gaseous } \\
\text { cloud with possibility of fire of table cloth \& stop of unit }\end{array}$ & Failure of the valve LCV-403A. \\
\hline $\begin{array}{l}2^{\text {nd }} \text { scenario: Damage to the D } 402 \text { balloon and stop } \\
\text { production. }\end{array}$ & Failure of the valve PCV- 401. \\
\hline $3^{\text {rd }}$ scenario: Balloon burst D-402 & $\begin{array}{l}\text { Untimely opening of the valve } \\
\text { TCV-410. }\end{array}$ \\
\hline
\end{tabular}

\subsection{Estimation of the frequencies of the initiating events}

In this step, the frequencies of the initiating events, Table 5, are determined from the ICSI 2009 data.

Table 5. Frequencies of initiating events [12]

\begin{tabular}{lll}
\hline Initiating Event & Frequency (/ year) & Note \\
\hline The failed valve LCV-403A & $1.0 \mathrm{E}-1$ & Unique value \\
\hline The failed valve PCV-401 & $1.0 \mathrm{E}-1$ & Unique value \\
\hline The failed valve TCV-410 & $1.0 \mathrm{E}-1$ & Unique value \\
\hline
\end{tabular}

\subsection{Identification of the independent protection layers}

After the identification of the safety barriers by the HAZOP method, these barriers are admitted as IPL. The independent protective layers retained in this work are the following:

a) Alarm \& Operator,

b) SIS Safety Instrument System,

c) Safety valves PSV401 A / B / C.

The probabilities of failure on demand (PDF) of these protective layers are calculated by the following approach:PFD calculation Emergency stop system PLC (SIS: LZLL-403)

Table 6. PFDs Emergency Stop System PLC (SIS: PZH-129) [12]

\begin{tabular}{lllll}
\hline Equipment & Architecture & $\boldsymbol{\lambda}:\left(\mathbf{h}^{-1}\right)$ Failure rate & Equation & PFD $_{\text {avg }}$ \\
\hline Level sensor & 1001 & $1.26 \mathrm{E}-06$ & $\mathrm{PFD}_{\mathrm{C}}=(\lambda * \mathrm{~T}) / 2$ & 0.0055 \\
\hline Treatment unit (PLC) & 2003 & $4.0 \mathrm{E}-08$ & $\mathrm{PFD}_{\mathrm{T}}=(\lambda * \mathrm{~T})^{2}$ & $1.22 \mathrm{E}-7$ \\
\hline Actuator (G-401 A/B) & 1002 & $3.6 \mathrm{E}-5$ & $\mathrm{PFD}_{\mathrm{A}}=[(\lambda * \mathrm{~T}) * 2] / 3$ & 0.033 \\
\hline Actuator (H-401) & 1001 & $3.2 \mathrm{E}-5$ & $\mathrm{PFD}_{\mathrm{C}}=(\lambda * \mathrm{~T}) / 2$ & 0.14 \\
\hline
\end{tabular}

It is assumed that the interval between test $(\mathrm{T})$ equals one year $(\mathrm{T}=8760 \mathrm{~h})$.

$$
\begin{aligned}
& \mathrm{PFD}_{(\mathrm{SIS})}=\mathrm{PFD}_{\mathrm{C}}+\mathrm{PFD}_{\mathrm{T}}+\mathrm{PFD}_{\mathrm{A}} \\
& \mathrm{PFD}_{(\text {SIS }}=0.18
\end{aligned}
$$

The PFD's of these protective layers (Alarm \& Operator and safety valves PSV402 A / B / C) are calculated from the fault tree according to the PFD's of the "database".

The Table 7 shows the loop architect and the PFDs of each component, which allows us to feed the ADD and compute the overall PFD's of each IPL.

Figure 10 shows the application of the AdD method relative to the Alarms \& Operator scenario which is grouped together as a single IPL.

Figure 11 illustrates the application of the AdD method for the three PSV-402 A/B/C safety valves that are grouped together as a single IPL. 
RECENT, Vol. 21, no. 3(62), 2020

Table 7. PFD of IPL [12]

\begin{tabular}{llll}
\hline The loop & Component & Architecture & $\begin{array}{l}\text { Probability of failure } \\
\text { PFD }_{\text {avg }}\end{array}$ \\
\hline \multirow{2}{*}{ Alarm \& operator } & Alarm (LAL_403 et LALL_404) & 1002 & $1 \mathrm{E}-3$ \\
\cline { 2 - 4 } & Operator & 1001 & 0.1 \\
\hline \multirow{2}{*}{ PSV-402 A/B/C } & A & 1003 & $1 \mathrm{E}-2$ \\
& C & & \\
\hline
\end{tabular}

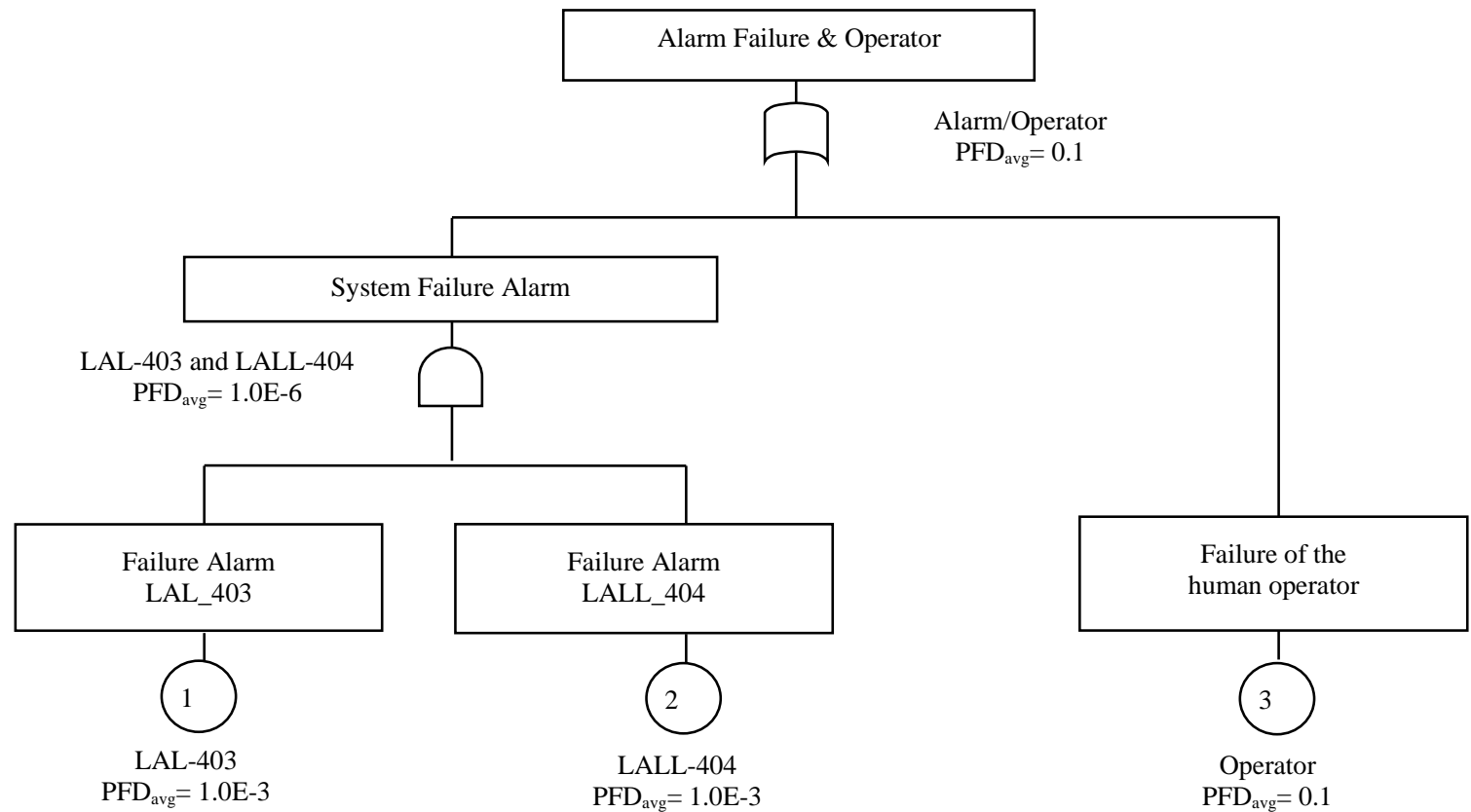

Fig. 10. AdD for IPL (Alarm / Operator) [12]

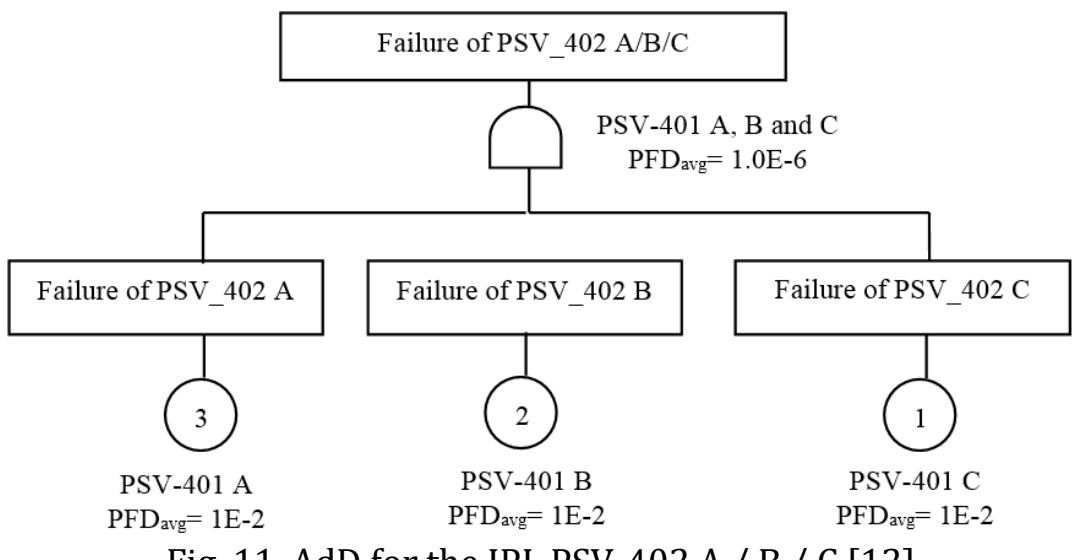

Fig. 11. AdD for the IPL PSV-402 A / B / C [12]

The PFDs of these IPLs are given in Table 8.

Table 8. The PFDs of the IPLs [12]

\begin{tabular}{ll}
\hline IPL & PFD $_{\text {avg }}$ \\
\hline Alarm \& Operator & 0.1 \\
\hline Emergency stop system (SIS: LZLL-403) & 0.18 \\
\hline Safety valves (PSV401 A / B / C) & $1.0 \mathrm{E}-06$ \\
\hline
\end{tabular}




\subsection{Calculation of the frequency of each accident scenario}

Accident scenarios are represented by the AdE method (see Figures 12, 13 and 14).The choice of this method allows us to give a clear representation of the sequence of events by specifying their frequencies and consequently the frequency of each scenario.

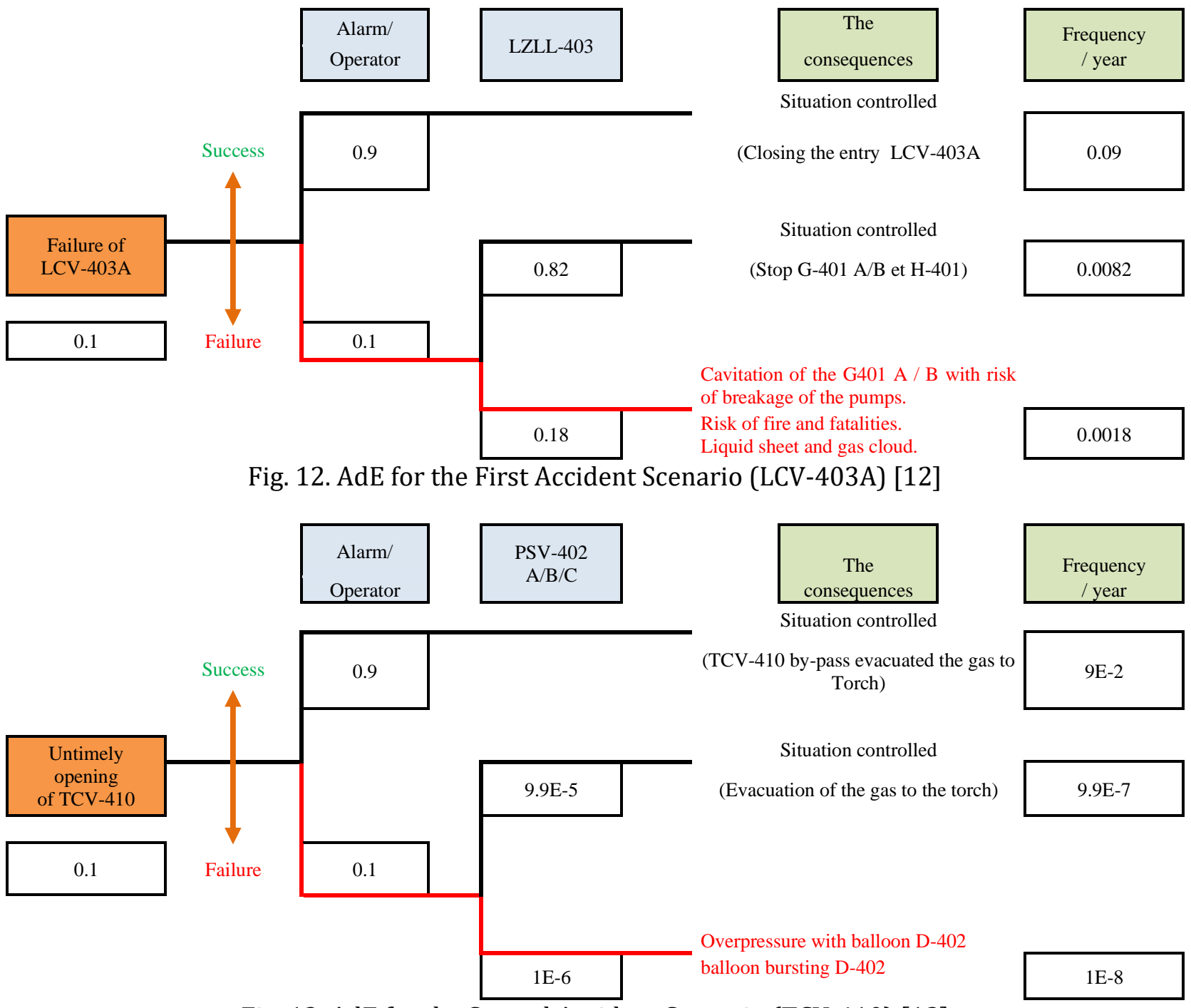

Fig. 13. AdE for the Second Accident Scenario (TCV-410) [12]

The frequencies of accident scenarios 1, 2 and 3 are calculated by multiplying the probabilities of the events of the same path. For accident scenarios with similar consequences, the total frequency is estimated by adding the frequencies of the consequences of each scenario.

The results of this analysis are given in Table 9.

Table 9. Frequencies of accident scenarios [12]

\begin{tabular}{|c|c|c|}
\hline Scenarios & Consequences & $\begin{array}{l}\text { Frequency of consequences } \\
\text { (../year) }\end{array}$ \\
\hline $1^{\text {st }}$ & $\begin{array}{l}\text { - Cavitation of the G-401 A / B with risk of } \\
\text { breakage of pumps, } \\
\text { - Liquid sheet and gaseous cloud, } \\
\text { - Risk of fire and fatality. }\end{array}$ & 0.0018 \\
\hline $2^{\text {nd }}$ & - Overpressure of the balloon D- 402 & \multirow{2}{*}{$1.1 \mathrm{E}-7$} \\
\hline $3^{\text {rd }}$ & - Balloon bursting D-402 & \\
\hline
\end{tabular}




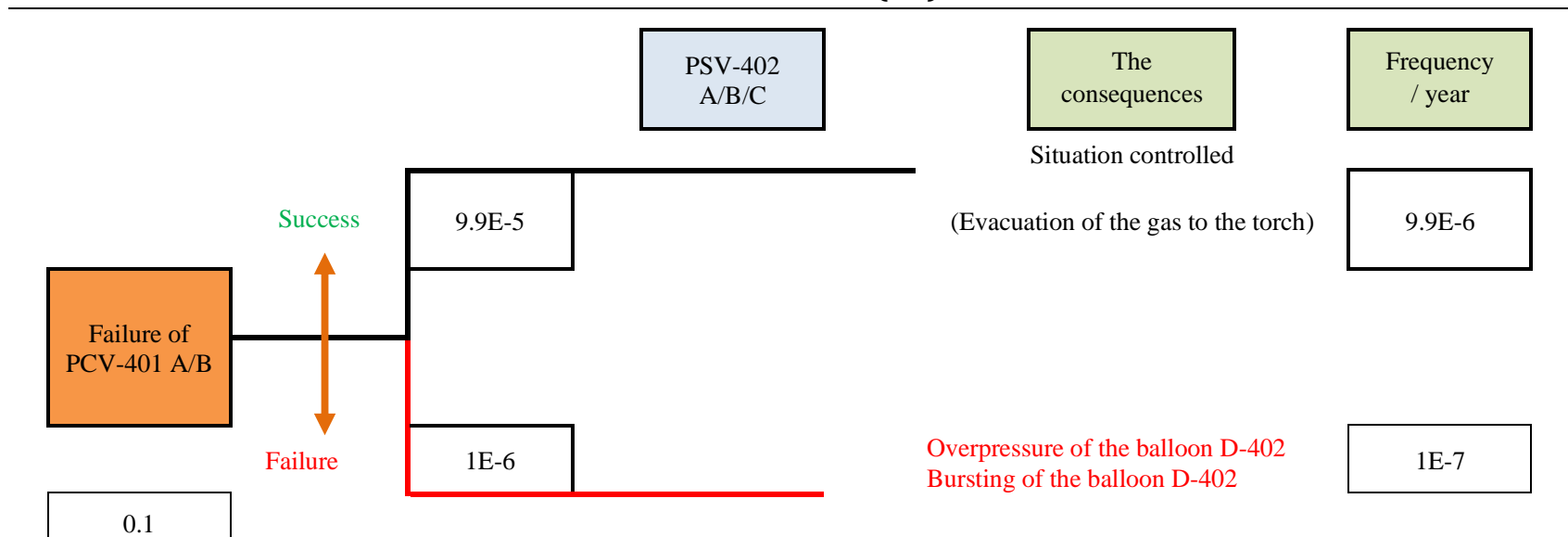

Fig. 14. AdE relating to the third accident scenario (PCV-401 A / B) [12]

\subsection{Assessment of accident scenarios against the risk matrix}

The assessment of accident scenarios established by the LOPA method will be carried out in relation to the acceptability criteria. It can be seen that all accident scenarios are tolerable risks, so you have to add prevention barriers or additional protection or reinforce the existing barriers to ensure a higher level of safety. Table 10 shows the risk zone of each scenario according to the risk matrix.

Table 10. Risk area for each scenario [12]

\begin{tabular}{|l|l|l|l|}
\hline Scenarios & Gravity Scale & Frequency range & Risk Area \\
\hline $\mathbf{1}^{\text {st }}$ & G3 & P2 & Tolerable \\
\hline $\mathbf{2}^{\text {nd }}$ & G4 & P1 & Tolerable \\
\hline $\mathbf{3}^{\text {rd }}$ & G4 & P1 & Tolerable \\
\hline
\end{tabular}

\section{Conclusion}

In this work, we tried to evaluate the performance of the safety barriers in a real case. We began by determining the causes and their possible consequences using the HAZOP method, and then we calculated the PFDs of the IPLs from the failure tree. Accident scenarios are represented by the tree of events (AdE) method which allows us to give a clear representation of the sequence of events by specifying their frequencies and consequently the frequency of each scenario.

To ensure a safer state ( $1^{\text {st }}$ scenario), you must:

$\checkmark$ Reducing the probability by adjusting the means of prevention, in this case, the existing SIS must be strengthened to become more efficient.

$\checkmark$ Add a new level sensor (LI), which controls the very low level in column C-401 and transmits a signal to a new PLC that operates on the valve (TCV-404).

$\checkmark$ Add protective means to minimize the severity of the risk by offering an automatic or semiautomatic deluge system with the flame detector.

The main recommendation for both scenarios ( $2^{\text {nd }}$ and $3^{\text {rd }}$ ) is:

- Install remotely operable line shut-offs with capacity drain to the torch in case of overpressure.

- Install gas and fire detectors combined with automatic shutdown of installations in the event of an alarm with isolation and depressurization of equipment.

Finally, it is important to ensure an efficient maintenance and inspection system for gas and fire detectors.

\section{References}

1. Brissaud F., Lanternier B. (2009): Les probabilités de défaillance comme indicateurs de performance des Barrières techniques de sécurité - approche analytique (The probabilities of failure as performance indicators of technical safety barriers - analytical approach). 8ème congrès international QUALITA 2009, Besançon, France, https://www.researchgate.net/publication/29601954_Les Probabilites Defaillance comme Indicateurs de Performance des Barrieres Techniques de Securite - Approche Analytique(in French) 
2. Process Safebook 1 (2013): Sécurité fonctionnelle dans l'industrie des procédés: Principes, normes et mise en ceuvre (Functional safety in the process industry: Principles, standards and implementation). Rockwell Automation, https://literature.rockwellautomation.com/idc/groups/literature/documents/rm/safebkrm003 -fr-p.pdf (in French)

3. Iddir 0. (2012): Études des dangers: mesures de maîtrise des risques (barrières) (Hazard studies: risk control measures (barriers)). https://www.techniques-ingenieur.fr/fiche-pratique/environnement-securite-th5/ maitriser-le-risque-chimique-management-sante-et-securite-dans-l-entreprise-dt118/etudes-des-dangersmesures-de-maitrise-des-risques-barrieres-0543/ (in French)

4. INERIS (2018): Évaluation de la performance des Barrières Techniques de Sécurité OMEGA 10 (Performance evaluation of Technical Safety Barriers OMEGA 10). Study report $\mathrm{N}^{\circ}$ DRA-17-164432-10199B, https://www.ineris.fr/sites/ineris.fr/files/contribution/Documents/DRA-17-164432-10199B OMEGA10 VF.pdf

5. INERIS (2006): OMEGA 7 - Méthodes d'analyse des risques générés par une installation industrielle (OMEGA 7 Methods for analyzing the risks generated by an industrial installation). Study report $\mathrm{N}^{\circ}$ INERIS-DRA-2006P46055-CL47569, https://www.ineris.fr/sites/ineris.fr/files/contribution/Documents/rapport omega 7-2.pdf (in French)

6. Center for Chemical Process Safety of the American Institute for Chemical Engineers (2003): Layer of Protection Analysis: Simplified Process Risk Assessment. ISBN-10: 0-8169-0811-7, ISBN-13: 978-0-8169-0811-0

7. Wei C., Rogers W.J., Mannan M.S. (2008): Layer of protection analysis for relative chemical risk assessment. Journal of Hazardous Material, Vol. 159, is. 1, pp. 19-24, https://doi.org/10.1016/j.jhazmat.2008.06.105

8. Willey R.J. (2014): Layer of Protection Analysis. Procedia Engineering, ISSN 1877-7058, Vol. 84, pp. 12-22, https://doi.org/10.1016/i.proeng.2014.10.405

9. Iddir 0. (2012): Méthode LOPA: principe et exemple d'application (LOPA method: principle and example of application). SE4075 v1, https://www.techniques-ingenieur.fr/base-documentaire/environnement-securiteth5/methodes-d-analyse-des-risques-42155210/methode-lopa-principe-et-exemple-d-application-se4075/ (in French)

10. *** (2008): Evaluation des performances des Barrières Techniques de Sécurité (DCE DRA-73) Evaluation des Barrières Techniques de Sécurité- $\Omega 10$ (Performance evaluation of Technical Safety Barriers (DCE DRA-73) Evaluation of Technical Safety Barriers $-\Omega 10$ ). Study report $N^{\circ}$ DRA-08-95403-01561B, http://www.memento dumaire.net/wp-content/uploads/2012/03/0mega 10 Evaluation BTS v2 0908 web.pdf (in French)

11. Lanternier B., Adjadj A. (2007): Allocation de SIL requis sur un réseau de refroidissement à l'ammoniac conformément à la norme CEI 61511 (Allocation of SIL required on an ammonia cooling network in accordance with IEC 61511). Congrès International sur l'ingénierie des risques industriels (CIRI 2007), Montréal, Canada, pp.286-296, https://hal-ineris.archives-ouvertes.fr/ineris-00976203/document(in French)

12. Dehimi I., Aggoun H. (2016): Contribution à l'évaluation des barrières de sécurité par la méthode LOPA (Contribution to the evaluation of safety barriers by the LOPA method). Master thesis, Risk and Environment Management, Department of Transport Engineering, Université des Frères Mentouri Constantine, Algeria

13. SONATRACH Division Production Direction Régionale Tin Fouyé Tabankort (TFT). A study by Khoudiri Mohamed, 2014

\section{Acronymes}

$\begin{array}{llll}\text { AdE } & \text { : Events Tree } & \text { ESD } & \text { : Emergency Stop System } \\ \text { BTS } & \text { : Security Technical Barriers } & \text { FSLL } & \text { : Flow Switch Low Low } \\ \text { DCS } & \text { : Distributed Control Systems } & \text { HAZOP } & \text { : Hazard and Operability Study } \\ \text { IPL } & \text { : Independent Protection Layer } & \text { LIH } & \text { : Level Indicator High } \\ \text { LAH } & \text { : Level Alarm High } & \text { LIL } & \text { : Level Indicator Low } \\ \text { LAL } & \text { : Level Alarm Low } & \text { LOPA } & \text { : Layers Of Protection Analysis } \\ \text { LALL } & \text { : Level Alarm Low Low } & \text { LT } & \text { : Level Transmitter } \\ \text { LCV } & \text { : Level Control Valve } & \text { LZLL } & \text { : Level Emergence Low Low } \\ \text { LIC } & \text { : Level Indicator Controller } & \text { NC } & \text { : Level of Trust } \\ \text { PAL } & \text { : Pressure Alarm Low } & \text { PID } & \text { : Piping and Instrumentation Diagram } \\ \text { PCF } & \text { : Fluid Circulation Plan } & \text { PIC } & \text { : Pressure Indicator Controller } \\ \text { PCV } & \text { : Pressure Control Valve } & \text { PLC } & \text { : Programmable Logic Controller } \\ \text { PFH } & \text { : Probability of Failure per Hour } & \text { PSV } & \text { : Pressure Safety Valve } \\ \text { PFD } & \text { : Probability of Failure on Demand } & \text { TAH } & \text { : Temperature Alarm High } \\ \text { SIF } & \text { : Safety Instrumented Functions } & \text { TAHH } & \text { :Temperature Alarm High High } \\ \text { SIL } & \text { : Safety Integrity Level } & \text { TCV } & \text { :Temperature Control Valve } \\ \text { SIS } & \text { : Safety Instrumented System } & \text { TSHH } & \text { : Temperature Switch High High }\end{array}$

